\section{The placebo effect: $I$. Situational anxiety and model behavior}

\author{
BRUCE JOHN MORRISON* and STEPHEN B. WALTERS \\ Miami University, Oxford, Ohio 45056
}

The placebo effect is a strong phenomenon not dependent on the anxiety state of the S or a model's behavior for its existence. Ss do, however, seem to use the behavior of others as a reference point for judging their own internal state. When the model's behavior is perceived as being close to the S's, assimilation of perceived behavior characteristics occurs. If the model's behavior is perceived as distant from the S's own internal state, there seems to be a contrast effect; he perceives himself as markedly different from the model.

Although the reality of a placebo effect has been known for many years, little research has been done on the phenomenon itself.

Theories, such as Shapiro's (1964), have succinctly stated that the factors involved are expectations, conviction, suggestibility, and personality. However, a review of the literature seems to indicate little relationship between personality factors and the placebo effect. Honigfeld (1964) has hypothesized the placebo effect as part of the "drug giving ritual." Lowinger \& Dobie (1966) have stated that this phenomenon is an effect of the physician as well as the recipient. Guy (1967) has concluded that there is no identifiable class of placebo reactors, and the most important variable seems to be experimental set. Ondarza-Linares (1967) has suggested that the S's expectations may themselves be factors in determining the quality of a placebo effect obtained. Rickels (1968) and Overall et al (1969) have concluded that placebo effects were concomitantly found with Ss with low verbal IQ and low anxiety, as measured by the Taylor Manifest Anxiety Scale. Halm (1968) found no relationship between field dependency and placebo effect. In each case, the placebo effect was seen as enormously complex.

The failures of previous research to isolate those factors responsible for the placebo effect may be due to an attempt to study those factors individually. It is suggested that it may be necessary to study many variables together in a context which permits their interaction to occur as they would under nonexperimental conditions.

If the placebo effect is viewed as a social phenomenon wherein the placebo recipient models his behavior

* Address requests for reprints to Bruce Jobn Morrison, Vice President and Director of Consumer Research Operations, Griswold Eshleman Company, 55 Public Square, Cleveland, Ohio 44113. and subjective feelings on the basis of cues he receives from other persons, then it would be expected from previous social psychological studies that a model and his behavior along with the anxiety state of the $S$ should affect the placebo phenomenon. It is therefore hypothesized that the type of suggestion given, the overt behavior of the model, and the anxiety state of the $S$ should affect the placebo effect. SUBJECTS

As part of their course requirements, 180 male and female students from introductory psychology classes at Miami University served as Ss without prior knowledge that this was a drug study. DESIGN

The experimental design was a 3 by 3 by 2 factorial utilizing three levels of drug (1/3 no pill, $1 / 3$ stimulant pill, and $1 / 3$ depressant pill), three levels of model ( $1 / 2$ no model, $1 / 4$ hyperactive model, and $1 / 4$ depressed model), and two levels of anxiety ( $1 / 2$ no shock and $1 / 2$ shocked). In each of these conditions, the pill consisted of a 10-mg capsule of milk sugar.

\section{PROCEDURE}

Each $S$ was told that the study was aimed at examining the effects of a quick-acting drug. The $S$ was then read a statement to the effect that the drug to be taken was safe and had been approved by the Federal Food and Drug Administration. Each $\mathbf{S}$ was then asked whether he had any previous history of heart attacks, sugar diabetes, mental illness, or any other physical illnesses which might exclude him from the study. No Ss reported any health problems, and all were experiment. Upon the negative answer, the $E$ then hooked up the $S$ to the shock apparatus, saying that the purpose of the equipment was to record heartbeat rate. One-half of the Ss were then given two 1-sec the shock, these Ss were informed that the equipment was malfunctioning and that they were to report if a shock included in the remainder of the presentations of shock. Upon receiving occurred again. Ss not receiving shock were not informed that anyone had been shocked by the equipment. All Ss were then led to a sink outside the experimental room, upon which were two unmarked bottles of pills and dispensary cups. One-third of the Ss were given a placebo and told it was a stimulant, and one-third were given the placebo and told it was a depressant. It was at this point that the Ss in the no-pill condition were informed that they would not receive a drug. All instructions and procedures for them up to this point and after it were identical to the pill conditions. All Ss were then taken to a "waiting room, "hooked up to a fake heart-rate recorder junction box, and left there for $10 \mathrm{~min}$, supposedly waiting for the pill, if ingested, to take effect. For one-half of the Ss, a model (either hyperactive or depressed) was already in the waiting room and remained with the $S$ for 5 min. After this length of time, the model was removed by an alternate $\mathrm{E}$. At the end of the 10-min period, all Ss were taken back to the experimental room and administered a simple reaction-time test and two rating-type questionnaires. At the end of the experimental session, the $S$ was debriefed by being informed that he had served in the control group and had received a placebo instead of the actual medication. After debriefing, all Ss were asked to, and did, sign a pledge that they would not discuss the experiment with anyone. To further reduce the possibility of Ss' not being naive, the entire experiment was run in only 10 days.

\section{RECORDING}

The first questionnaire consisted of a list of possible side effects (such as heartbeat rate, respiration rate, sweating of the hands, and other effects known to be associated with different kinds of drug usage), in which $S$ indicated his perceived state b'v checking a change/no change and increase or decrease continuum.

The second questionnaire was one form of the Activation-Deactivation Adjective Check List (AD-ACL), a self-report test of momentary states of activation (Thayer, 1967) which has been shown to correlate with heart rate and the GSR. The test consists of a set of 35 activation-descriptive adjectives which the $S$ is asked to rate on a 4-point scale according to how it describes his feelings at that moment. This group of adjectives has been factor-analyzed a number of times by Thayer, and in each case four orthogonal major factors are extracted: (1) general activation (lively, active, full of pep, energetic); (2) high activation (clutched-up, jittery, stirred-up); (3) general deactivation (at rest, still leisurely); 
Changes in Drug Side Effects as a Function of Suggestion and/or Model

Mean

from Norm

Condition

Stimulant Drug Only

Stimulant Drug and Stimulant Model

Stimulant Drug and Depressant Model

Stimulant Model Only

Depressant Drug Only

Depressant Drug and Depressant Model

Depressant Drug and Stimulant Model

Depressant Model Only

No Drug and No Model
$-9.4$

$\mathbf{3 . 8 7}$

$-6.1$

$-8.3$

$-16.9$

$-10.1$

$-17.9$

$-\mathbf{5 . 5}$

$-3.9$ and (4) deactivation-sleep (sleepy, tired, drowsy).

\section{RESULTS}

Although a comparison of pre- and postexperimental simple reaction-time tests yielded no statistically significant differences, there were significant differences on the drug side-effect checklist and the activation-deactivation scale.

Table 1 indicates perceived increase or decrease in the symptom checklist as a function of the different drugs by model conditions. This score is the simple summation algebraically of the subjective ratings of stimulation $(t)$ and depression (-). Significant differences were found for drug suggestion $(\mathrm{F}=12.343, \mathrm{df}=2 / 107$, $\mathrm{p}<.001)$ and Drug by Model interaction $(\mathrm{F}=3.275, \quad \mathrm{df}=4 / 107$, $\mathrm{p}<.05)$. There were no significant main effects for model or anxiety. In conditions where the drug was called a stimulant and the model acted hyperactive, Ss had a tendency to check stimulant-directed symptoms. In conditions where the drug was called a depressant and the model acted hypoactive, the opposite effect was noted. It should be pointed out that the depressant set seems to be a more powerful variable. In mismatched conditions (i.e., depressant pill, stimulant model; stimulant pill, depressant model), not only did the depressant model condition have more effect on $\mathrm{S}$ than the stimulant model, but the depressant condition in general seemed to be more influential than the stimulant condition.

An analysis of variance on the stimulant and depressant factors of the AD-ACL yielded significant main effects for drug suggestion on both factors $(F=5.195, \mathrm{df}=2 / 108, \mathrm{p}<.01$ and $\mathrm{F}=4.758, \mathrm{df}=2 / 108, \mathrm{p}<.01$, respectively). On both factors, there were no significant main effects for model or anxiety, and nor were there any significant interactions. Table 2 shows a comparison of treatment means for different experimental conditions on the activation and deactivation factors of the AD-ACL, respectively. All Ss seem to have come to the experimental situation highly activated and the presentation of any placebo lowered activation regardless of the placebo condition. Again, in each case, Ss given placebos called "depressant" were more affected than those given placebos called "stimulant."

\section{DISCUSSION}

The results of this experiment show the reality and strength of the placebo effect. Despite the inability of placebos to affect measures of simple reaction time, "drug effects" were attested to by the number and degree of perceived changes checked by Ss on the symptom checklist and the $\mathrm{AD}-\mathrm{ACL}$. The finding that $\mathrm{Ss}$ in the stimulant drug-only condition presented more depressed characteristics than Ss in the no-drug condition can only be explained by the nature of the experiment itself. It must be remembered that Ss reported to the experiment without prior knowledge that it was a drug study. The experiment was thus such that all Ss participating in the experiment initially experienced a high degree of ambiguity and uncertainty resulting in higher activation levels. This is supported by data obtained on the AD-ACL and is in line with a number of studies that show Ss to prefer information about the experimental design and outcome even when the information has no apparent instrumental value (Pervin, 1963; Elliot, 1966; Lanzetta \& Driscoll, 1966).

Thus, any suggestion that would clarify the situation would also probably lower the activation level or tension level (Elliot, 1966). This is precisely what seems to have happened. Being given what was purported to be a stimulant drug clarified the situation and lowered the activation level to some degree. Being given what was purported to be a depressant drug also clarified the situation but produced a much greater effect because of the nature of the suggestion itself. The "search" for information and clarity by $\mathrm{Ss}$ in the no drug control condition is attested to by reports of verbalizations ranging from beliefs that $S s$ were being watched on closed-circuit television, beliefs that Ss were involved in disguised personality testing, to beliefs that $\mathbf{E}$ was waiting for $\mathbf{S}$ to demand to take a pill. It is also interesting to note that while no Ss in the drug conditions refused to take a pill, at least four $\mathrm{Ss}$ in the no-pill condition requested, and in one instance demanded, to be switched to a "drug taking" condition.

In matched drug and model conditions, those Ss tested with models were more stimulated than those Ss without models regardless of the conditions. While possible explanations could be social facilitation of activation level due to the mere presence of a model or anxiety caused by the danger of taking either a depressant or a stimulant drug (attested to by the extreme behavior of the model), the data do not seem to support either one. Both explanations would predict a significant main effect for model which was not found. In addition, both explanations would have difficulty explaining the Drug by Model interaction which was found on the symptom checklist.

A more plausible explanation is that Ss used the model's behavior as a standard by which to evaluate their own internal feelings. If $S$ perceived himself as being close to the model, he would assimilate some of the model's characteristics. On the other hand, if $S$ perceived himself distant from the model, he reported behavior in the opposite direction. This is noted often in an individual's own subjective experience. After one or two alcoholic drinks, one feels high and happy when placed with others in the same state but very sober when talking to a drunk. Since all Ss were initially highly activated and the models were extremely hyper- or hypoactivated, it is not surprising that the stimulated

Table 2

Mean Treatment Effects on the Stimulant and Depressant Factors of the Activation-Deactivation Scale

\begin{tabular}{|c|c|c|}
\hline $\begin{array}{l}\text { Treatment } \\
\text { Conditions }\end{array}$ & $\begin{array}{c}\text { Mean of } \\
\text { Stimulant } \\
\text { Treatment } \\
\text { Effects }\end{array}$ & $\begin{array}{c}\text { Mean of } \\
\text { Depressant } \\
\text { Treatment } \\
\text { Effects }\end{array}$ \\
\hline \multicolumn{3}{|l|}{ Drug } \\
\hline Stimulant & 1.9778 & .4667 \\
\hline Depressant & 1.1707 & 1.2927 \\
\hline No Drug & 2.055 & .5000 \\
\hline \multicolumn{3}{|l|}{ Model } \\
\hline Stimulant & 2.0286 & .8571 \\
\hline Depressant & 1.5667 & .5333 \\
\hline No Model & 1.9836 & .7869 \\
\hline \multicolumn{3}{|l|}{ Anxiety } \\
\hline Shock & 2.1500 & .7167 \\
\hline No Shock & 1.6667 & .7727 \\
\hline
\end{tabular}


effects were noted in all Drug by Model matched conditions.

If this explanation is correct, it is very similar to the contrast assimilation effect reported in attitudinal research (Hovland \& Pritzker, 1957). This effect refers to the finding that Ss are more willing to move in the direction of attitudes presented when they are perceived as close to their own. On the other hand, if the communications presented are perceived as being distant, Ss will actually move in the opposite direction. This tendency to accept or reject according to perceived closeness appears to be very similar to the behavior exhibited by Ss in the present study and strengthens the authors' belief that the placebo effect is a social phenomenon similar to persuasion, hypnotism, and experimental demand characteristics. It should be remembered, however, that although the placebo effect found in this experiment was quite strong, it did not seem to be totally dependent on any of the independent variables for its existence.

\section{REFERENCES}

ELLIOT, R. Effects of uncertainty about the nature and advent of a noxious stimulus (shock) upon heart rate. Journal of Personality \& Social Psychology, 1966, 3, 353-356.

GUYY G. H. Placebo proneness: Its relationship to environmental influences and personality traits. Dissertation Abstracts, 1967, B, 2137-2138.

HALM, J, The relationship of field articulation and affective placebo reaction. Dissertation Abstracts, 1968 $28 \mathrm{~B}, 4283$.

HONIGFELD, G. Non-specific factors in treatment: I. Review of social-psychological factors. Diseases of the Nervous System, 1964, 25, 225-239. HONIGFELD, $G$. Non-specific factors in treatment: I I. R eview of social-psychological factors. Diseases of the Nervous System, 1964, 25, 225-239. HOVLAND, C. I., \& PRITZKER, H. A. Extent of opinion change as a function of amount of change advocated. Journal of Abnormal Social Psychology, 1957, 54. 257-261.

LANZETTA, J. T., \& DRISCOLL, J. M. Preference for information about an uncertain but unavoidable outcome Journal of Personality \& Social Psychology, 1966, 3, 96-102.

LOWINGER, P.. \& DOBIE. S. What makes the placebo work? A study of placebo response rates. Archives of General Psychiatry, 1966, 20, 84-88.

ONDARZA-LINARES, J. I. effect placebo dans l'évaluation des drogues psychotropes (The placebo effect in evaluating psychotropic drugs). Annales de Therapeutique Psychiatrique, 1967, 3, $130-131$

OVERALL, J. E., HOLLISTER, L. E., KIMBELL, I., JR., \& SHELTON, J. Extrinsic factors influencing responses to psychotherapeutic drugs. Archives of General Psychiatry, 1969, 21, 89-94.

PERVIN. L. A. The need to predict and control under conditions of threat Journal of Personality, 1963, 31, 570-587.

RICKELS, K. Non-specific factors in drug therapy of neurotic patients. In $K$. Rickels (Ed.), Non-specific factors in drug therapy. Springfield, IIl: Charles C Thomas, 1968. Pp. 3-26.

SHAPIRO, A. A historic and heuristic definition of the placebo. Psychiatry, $1964,27,52-58$.

THAYER, R. E. Measurement of activation through self-report. Psychological Reports, $1967,20,663-678$. 